\title{
Social-Emotional Aspects of Quality of Life in Multiple Sclerosis
}

Heidemarie Lex, PhD, University of Utah, Department of Psychiatry, Salt Lake City; Beth Israel Medical Center Neurology, Boston, MA; Medical University of Graz, Department of Social Medicine and Epidemiology, Graz, Austria, heidi.lex@hsc.utah.edu, corresponding author

Sara Weisenbach, PhD, University of Utah, Department of Psychiatry, Satl Lake City, UT, sara.weisenbach@hsc.utah.edu

Jacob Sloane, MD, PhD, Beth Israel Medical Center Neurology, Boston, MA, sloane@bidmc.harvard.edu

Sana Syed, MD, Tufts Medical Center, Boston, MA; Beth Israel Medical Center Neurology, Boston, MA, sas670@mail.harvard.edu

Eva Rasky, MD, Medical University of Graz, Department of Social Medicine and Epidemiology, Graz, Austria, eva.rasky@medunigraz.at

Wolfgang Freidl, PhD, Medical University of Graz, Department of Social Medicine and Epidemiology, Graz, Austria, wolfgang.freidl@medunigraz.at

\begin{abstract}
Multiple sclerosis (MS) is an inflammatory auto-immune disease of the central nervous system. It leads to many impairments including physical, cognitive, psychological, and social challenges. Our study examined gender and cultural associations with quality of life (QoL), personal characteristics, and benefits from having MS among those with MS.

The study was conducted in Austria and the United States. The sample included 128 participants, 64 in each country, of whom 78 were women and 50 were men aged between 20 and 57 years. We used standard statistical tests, including analyses of covariance (ANCOVA) and partial correlations for the analysis of quantitative data. For the qualitative part of the survey we used semi-structured interviews, which we transcribed and coded to identify categories in the answers for qualitative analyses.

Austrian participants with MS perceived a higher social-emotional QoL in comparison to American participants. American participants expressed a higher self-esteem in comparison to Austrian participants. Men reported a lower ability to express love than women. Independent of sex/gender and nationality, participants reported benefits through the disease, especially with regard to improved compassion, mindfulness, improved family relations and lifestyle gains. The qualitative interviews revealed additional gender differences for coping with the illness; and in experiences, expectations, and challenges related to MS.

These insights can be used to develop targeted psychological and social support interventions aimed toward improving social-emotional QoL for persons with MS.
\end{abstract}

Keywords. Multiple sclerosis, social-emotional quality of life, gender, nationality, coping 


\section{Introduction}

Persons with MS often experience a diminished quality of life (QoL) due to the progression and symptoms of the illness (Campbell et al., 2014). There are several themes that have arisen in studies evaluating QoL among individuals with MS, including leaving or reducing paid employment (Irvine, Davidson, Hoy, \& Lowe-Strong, 2009), changes in social relationships (Charmaz, 1983), and altered perceptions of self (Boeije, Duijnstee, Grypdonck, \& Pool, 2002; Kralik, Koch, \& Eastwood, 2003).

Women are affected with MS approximately twice as often as men (Alcalde-Cabero, AlmazánIsla, García-Merino, de Sá, \& de Pedro-Cuesta, 2013; Stüve \& Oksenberg, 2006), and various studies have identified genetic and hormonal sex and gender differences in MS (Garcia-Montojo et al., 2013; Tillack et al., 2013). Most studies of MS have been conducted with women only, or have lacked the power to make gender comparisons (Irvine et al., 2009; Kralik et al., 2003; Reynolds \& Prior, 2003). Themes that have arisen among studies of only women have revealed topics such as missing being able to wear high heels, potentially indicating a sense of lost femininity (Irvine et al., 2009).

Coping is an essential mechanism for accepting and living with a chronic disease, such as MS. As Ahadi and colleagues (Ahadi et al., 2014) observed, individuals with MS use a variety of coping strategies in response to stressors, including problem-focused strategies, social support, planful problem solving, distancing, escape and avoidance, and self-control, but are less likely to use confrontation-based coping, relative to healthy comparisons. Stress management (MossMorris et al., 2009; Wagner et al., 2012) and self-management (Audulv, 2013; Corbin, Strauss, \& Hildenbrand, 2004; Sauter, Zebenholzer, Hisakawa, Zeitlhofer, \& Vass, 2008) strategies are important in response to constant adaptations to newly appearing health issues.

Figure 1 illustrates positive coping - self-management and stress-management strategies recommended for dealing with MS and how QoL can be improved.

\section{Helping other affected}

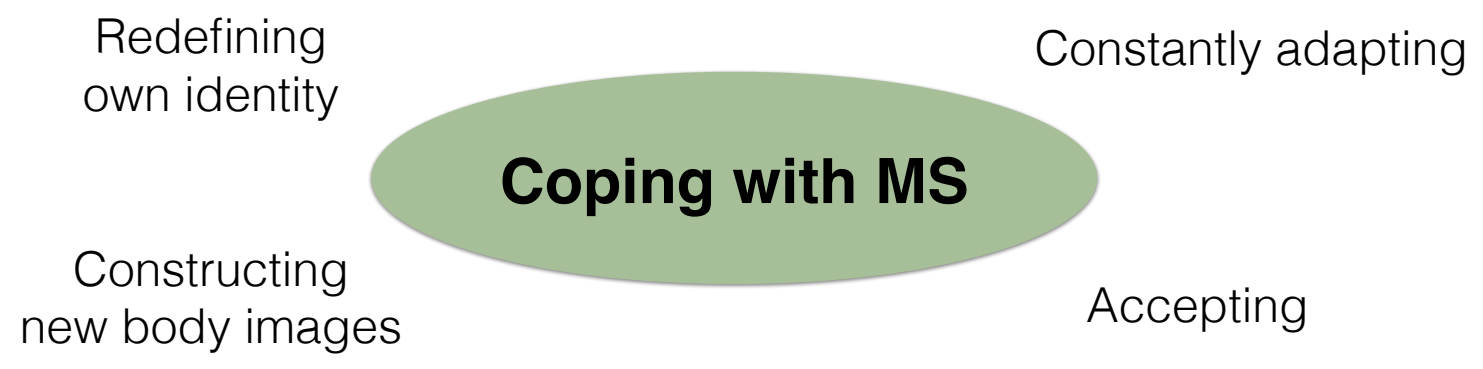

Making use of available support

Figure 1: Overview of Coping Styles used in MS and ways to improve quality of life with MS. 
One study has evaluated gender differences in stressors experienced and methods of coping with stressors (Matud, 2004). Women reported emotional coping styles more often and indicated less detached coping styles than men, while men described more emotional inhibition than women. The typical female coping style is more emotion-focused, whereas the male coping style is more detached.

Oriented on the latest literature we sought to draw a picture of MS as a whole and look beyond the mostly negative aspects of MS. We use the term social-emotional QoL, as we were primarily interested in psychological, emotional and social aspects of QoL among those with MS. For this reason, we used only aspects of questionnaires that relate to emotional and social QoL and personal characteristics. To extend knowledge about gender differences in QoL in MS, the first aim of the current study was to investigate gender differences in social emotional QoL, personal characteristics and ways of coping with the illness. We expected gender differences in socialemotional qol, self-esteem, the ability to express love and coping strategies for MS. Second, given the dearth of information about how culture and geographic location might impact QoL in MS, we also sought to explore QoL in those with MS living in Austria and the United States. We expected national differences in social-emotional qol, self-esteem and the ability to express love.

\section{Material and Methods}

\section{Participants}

Our study was conducted in Austria and the United States. The sample included 128 participants, 64 in each country, of whom 78 were women and 50 were men aged 18 to 57 years. In Austria, the sample was drawn from an inpatient neuro-rehabilitation clinic near Graz (Klinik Judendorf Strassengel) in Styria, which has dedicated physical therapy facilities for MS inpatients. The survey in the USA was conducted among outpatients at the Beth Israel Deaconess Medical Center (BIDMC) in Boston, MA, at the Multiple Sclerosis Center. Table 1 displays the key sample demographics, the distribution of participants in terms of gender, age and MS related characteristics.

\begin{tabular}{lll} 
& Austria & US \\
\hline Participants & 64 & 64 \\
Women & 39 & 39 \\
Men & 25 & 25 \\
Mean Age $(18-57)$ & $44.08(\mathrm{SD}=8)$ & $41.63(\mathrm{SD}=8.64)$ \\
Mean EDSS (0: no disability to 10: death) & $4.54(\mathrm{SD}=2.22)$ & $2.88(\mathrm{SD}=2.30)$ \\
Mean MS duration (years) & $12.1(\mathrm{SD}=7)$ & $9.33(\mathrm{SD}=7.4)$ \\
educational level N total (percentage) & & \\
No completed secondary education & $5(7.9 \%)$ & $3(4.7)$ \\
Completed secondary education & $48(76.2 \%)$ & $20(31.3 \%)$ \\
Completed college/university & $10(15.9 \%)$ & $41(64.1)$
\end{tabular}

Table 1: Key Sample Demographics. 
Inclusion criteria for participation was clinically definite MS diagnosis (including all MS types such as relapsing remitting, primary progressive or secondary progressive). Additionally, a strongly unbalanced gender ratio was avoided and only participants with the cognitive ability to complete the questionnaire and participate in the qualitative interview, were included.

\section{Procedure}

In both countries, the respective institutional review board approved the study (Ethics Commission of the Medical University of Graz and the IRB of the BIDMC in Boston). A written study information sheet as well as an oral explanation was given to the participants. Participants were informed that participation was voluntary, and their refusal to participate had no consequences for their continuing treatment or the relationship with their doctors. Participants were asked to read the informed consent form, ask clarifying questions, and provide their signature to express consent. To keep the survey situations as similar as possible and to exclude an interviewer bias, all interviews were conducted by the same person (HL) who speaks both languages fluently.

\section{Measures}

In quantitative questionnaires (see Table 2) and qualitative interviews (see Supplementary Materials), we asked questions about emotional and social aspects of QoL with MS, including self-esteem, the ability to express love, experiences with and changes since being diagnosed with MS. We selected Austria and the United States as study sites because in both regions MS is prevalent (Austria 98.5 per 100,000 population (Baumhackl, 2011), US, 90 per 100,000 population (Harsh \& Fox, 2000-2015) although they differ in language, social security systems, and healthcare provisions (i.e., Austria has a national healthcare system). The survey material was carefully translated and back-translated by independent parties, to guarantee consistent comparisons and interpretations of the results for the two subsamples.

\begin{tabular}{|c|c|c|}
\hline Questionnaires & Subscales Used & \# questions \\
\hline TPF-Trierer Persoenlichkeitsfragebogen (13) & sense of self-steem, ability to love & 23 \\
\hline $\begin{array}{l}\text { HALEMS/HAQUAMS (Hamburger Quality of } \\
\text { Life in MS) (14) }\end{array}$ & $\begin{array}{l}\text { social function, mood, handicap, } \\
\text { satisfaction with sex life }\end{array}$ & 16 \\
\hline $\begin{array}{l}\text { BFiMSS - Benefit Finding in Multiple Sclerosis } \\
\text { Scale (15) }\end{array}$ & $\begin{array}{l}\text { Compassion, Spiritual Growth, } \\
\text { Mindfulness, New Opportunities, Life Style } \\
\text { Gains, Family Relations Growth, Personal } \\
\text { Growth }\end{array}$ & 43 \\
\hline Sociodemographic Data & Gender, age, living situation, ... & 14 \\
\hline
\end{tabular}

Table 2: Overview of the quantitative instruments used

The first part of the questionnaire was composed of two subscales of the personality inventory TPF - Trierer Persönlichkeitsfragebogen (Becker, 1989b), specifically the sense of self-esteem scale and the ability to love scale. The TPF measures two aspects of personality: mental health and behavior control. The two scales used were translated to English. The questionnaire originally is in German, for age 17 to 80 years. The TPF has been primarily a clinical, rather than research measure, and we selected the two subscales that measure mental health (1989a). 
The second part of the questionnaire included parts of the questionnaire HAQUAMS-Hamburger Quality of Life in Multiple Sclerosis Scale (Gold et al., 2001). The subscales social function, mood, and handicap were used in the questionnaire. The third part of the questionnaire was the BFIMS S -Benefit Finding in Multiple Sclerosis Scale (Pakenham \& Cox, 2009). At the end of the quantitative questionnaire we asked questions eliciting sociodemographic data (see Table 2). We used the entire BFiMSS, though for stronger reliability we excluded two questions from further calculations (see Supplementary Materials for details). We realize that using subscales originally designed to be used as part of a larger scale can result in reduced reliability. We calculated Crombach's Alpha for all subscales. Reliability of all scales was moderate to good >.6 (For example self-esteem scale .86., ability to love scale .77, social-emotional qol scale .84).

The quantitative part of the study was followed by an one-on-one qualitative interview, where 26 open-ended questions were asked. We used content analysis to analyze qualitative data (Backman \& Hentinen, 2001; Elo \& Kyngäs, 2008), which is recommended when there are no previous studies dealing with the topic or when knowledge is fragmented. The questions asked dealt with the topics self-perception, living with $M S$, health literacy, subjective perception of the illness, health-related questions, questions related to QoL, and social support (see Supplementary Materials for details). We chose qualitative interviews to give participants the opportunity to name specific views and interpretations that may not be evident from questionnaires. The questions were selected based on current literature about challenges of living with chronic disease in general and MS in particular (Fortin et al., 2013). We used gender- neutral language.

\section{Data analysis}

To analyze the quantitative data, we used ANCOVAS for identifying gender and national differences (dependent variables: QoL scale, self-esteem and ability to love scales, benefit finding scale) and partial correlations to identify similarities in the sample. We controlled for possibly confounding variables including age, EDSS (Expanded Disability Status scale), MS duration, and educational level as covariates in the quantitative data analyses, as the subsamples differ (see Table 1). Missing data was replaced by using means of the specific scales of the subsample.

For the qualitative interview, we transcribed the answers to identify underlying categories. Specifically, similar answer patterns were put together in one category. We summarized answers dealing with similar topics in a category and counted the number of answers in each category. We analyzed qualitative data separately for Austria and USA. Controlling for confounding variables was not possible in the qualitative analyses which could bias conclusions on differences of these countries. (see Supplementary Material for interview details).

\section{Quantitative Results}

\section{Gender differences}

Concerning personal characteristics, men expressed a lower ability to love compared to women, who reported greater ease in expressing their feelings $(F(1,118)=12.74, p<.01$; women $\mathrm{M}=3.33$, men $\mathrm{M}=3.09$ ).

\section{Nationality differences}

Concerning personal characteristics, Austrians show significantly lower self-esteem than US participants $(\mathrm{F}(1,118)=4.94, \mathrm{p}<.05)($ see Table 3$)$. There are statistical tendencies in differences 
regarding social-emotional QoL in nationality $(\mathrm{F}(1,118)=3.76, \mathrm{p}=.06)$, with Austrians describing a higher social-emotional QoL in comparison to Americans (see Table 3).

AUSTRIA US

\begin{tabular}{lll|ll}
\hline Scales & Mean* & $\begin{array}{l}\text { Standard } \\
\text { Deviation }\end{array}$ & Mean* & $\begin{array}{l}\text { Standard } \\
\text { Deviation } \\
\text { Social-emotional QoL }\end{array}$ \\
Self-esteem & 2.1671 & 0.69448 & 2.4111 & 0.61937 \\
& 2.67 & 0.06 & 2.88 & 0.06
\end{tabular}

Table 3: Social-emotional QoL and Self-esteem in Austria and the United States.

* low mean values on the scale 'social-emotional Qol' describe a high social-emotional qol, high mean values a low social-emotional qol (scale 1-5). Low mean values on the scale 'self-esteem' describe a low self-esteem, high mean values a high self-esteem (scale 1-4).

\section{Similarities among the two sample sites}

In general, persons with high self-esteem also tended to show a high social-emotional QoL (see Table 4). Those receiving social support were more likely to report improved mindfulness and family relations growth since having MS, and persons receiving social support also reported a high self-esteem and a high ability to express love (see Table 4).

\begin{tabular}{lll} 
Correlation Self-Esteem with ... & Correlation & Significance \\
\hline ... Social-emotional QoL $*$ & -0.59 & 0.00 \\
Correlations Social Support with ... & & \\
\hline ... Self-esteem & 0.32 & 0.00 \\
$\ldots$ Ability to love & 0.20 & 0.03 \\
$\ldots$ Mindfulness (BFIMSS scale) & 0.18 & 0.05 \\
$\ldots$ Family Relat. Growth (BFIMSS scale) & 0.36 & 0.00
\end{tabular}

Table 4: Correlation of Self-esteem with Social-emotional QoL and correlations of Social Support with Self-esteem, Ability to Love, Mindfulness, Family Relations Growth.

*a high social-emotional qol is described by low values. In this case, what the negative correlation expresses is that high qol goes along with a high self-esteem and a low qol goes along with a low self-esteem.

For all correlations $\mathrm{Df}=118$.

Participants found benefits in having MS especially regarding compassion $(\mathrm{M}=2.19, \mathrm{SD}=.05)$, mindfulness $(\mathrm{M}=2.16, \mathrm{SD}=0.04)$, life style gains $(\mathrm{M}=2.37, \mathrm{SD}=0.05)$, family relations growth $(\mathrm{M}=2.09, \mathrm{SD}=0.04)$ and personal growth $(\mathrm{M}=2.03, \mathrm{SD}=0.04)$. Mean values $(\mathrm{M})>2$ describe improvements on these subscales since having MS (rating scale: $1=$ not at all, $2=$ somewhat, $3=a$ great deal). 


\section{Qualitative Results}

We present the qualitative data separately for Austria and the US. Statistical gender calculation of the coping strategies showed no significant differences, but an obvious tendency in gender differences can be observed in the figures.

\section{Gender similarities and differences in Austria}

As can be seen in Figure 2, in Austria more women than men pointed out ambivalent, resigned acceptance as a strategy for coping with MS (women AT 32\%, men AT 16\%). Acceptance in general was pointed out by more men than women (women AT 62\%, men AT $80 \%$ ). The categories identified in the interviews represent all responses from all participants.

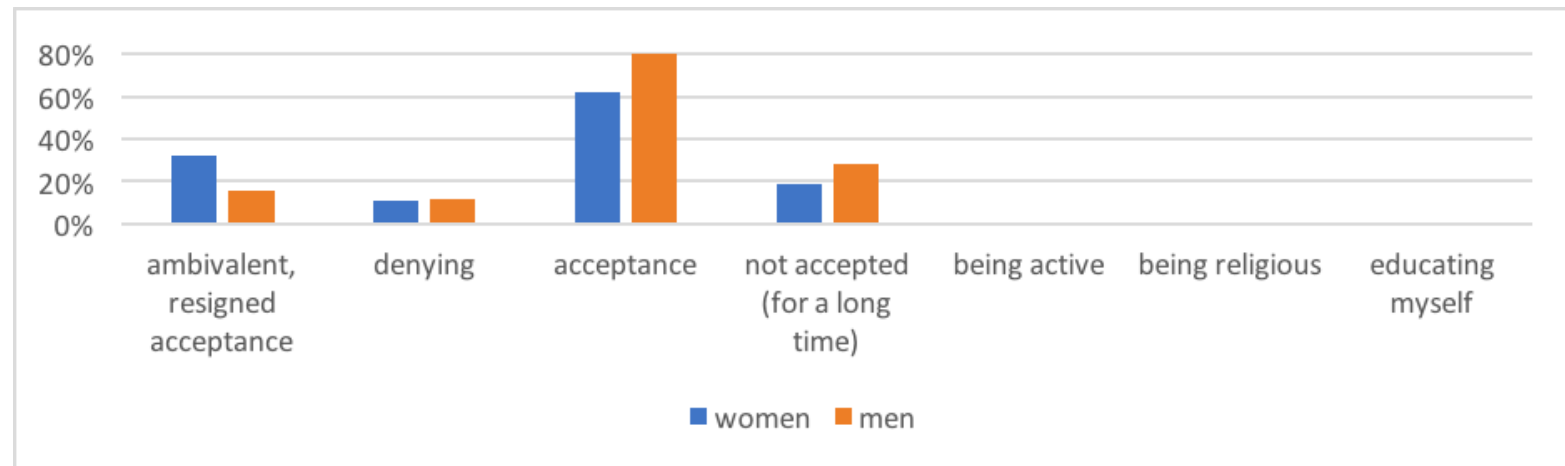

Figure 2: Coping with multiple sclerosis divided by sex in Austria. Women AT N=37, Men AT N=25.

\section{Gender similarities and differences in the US}

More men than women in the US (women US 5\%, men US 20\%) pointed out denial as a coping strategy for MS (Figure 3). Additionally, more men than women pointed out ambivalence, resigned acceptance (women US 15\%; men US 28\%) (quote: 'Tears, anger, I probably act out on occasion (P laughs), and determination, sometimes I get stubborn, more stubborn than normal, usually I don't slow down as much as I could and push through when probably sometimes I should step back.' (US female), as a coping strategy for MS. More women in comparison to men pointed out acceptance (women US 54\%, men US 40\%) and being active (women US 31\%, men US 28\%) (see Supplementary Material for more quotes)

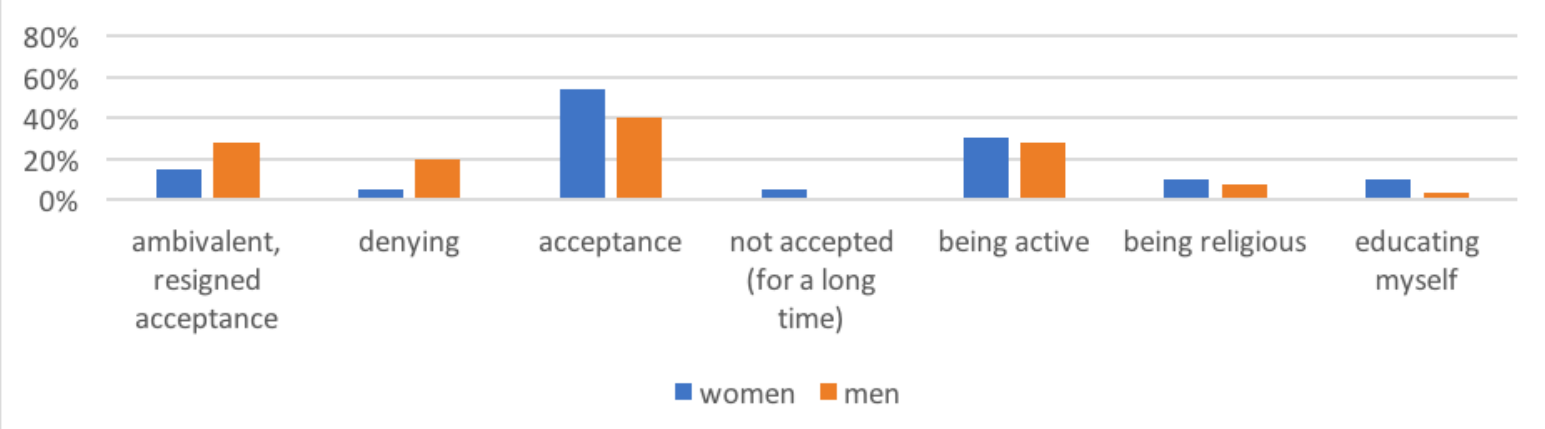

Figure 3: Coping with multiple sclerosis divided by sex in the US. Women USN=39, Men USN=25 
The categories identified in the interviews represent all responses from all participants.

For both sample sites, stress was mentioned frequently as a perceived cause for worsening symptoms of MS or even causing MS. Furthermore, negative experience with medical personnel was reported in both sample sites (see Supplementary Materials for details).

\section{Discussion}

We found that persons with MS in Austria reported a higher social-emotional QoL in comparison to US participants, while persons from the US expressed a higher self-esteem than Austrian participants. Women described a higher ability to express love than men. Independent of sex/gender and nationality, participants reported benefits through the disease, especially with regard to compassion, mindfulness, improved family relations, lifestyle gains and personal growth. The qualitative interviews further supported gender differences in coping strategies for MS.

\section{Quality of Life and Personalized Psychological Interventions}

Oriented on our study results we suggest developing personalized interventions for those with MS that empower self-esteem. Maintaining a high social-emotional QoL should be a goal for those with MS and their social environment, as also shown by various other studies (Boeije et al., 2002; Charmaz, 1983; Grech et al., 2016; Irvine et al., 2009; Kralik et al., 2003; Madan \& Pakenham, 2014; Reynolds \& Prior, 2003; Rintell, Frankel, Minden, \& Glanz, 2012; Strober, 2016). Itappears beneficial to offer personalized interventions oriented toward unique needs of women and men to improve their QoL.

A positive relationship between psychological interventions and physiological symptoms of MS was identified (Pagnini, Bosma, Phillips, \& Langer, 2014). Especially cognitive behavioral therapy (CBT) may be helpful for adjusting, and coping with, MS, improving sleep quality and reducing stress (Abbasi, Alimohammadi, \& Pahlavanzadeh, 2016; Moss-Morris et al., 2013; Thomas, Thomas, Hillier, Galvin, \& Baker, 2006). Abbasi et al. ( 2016) identified the following CBT interventions as effective to improving sleep quality in persons with MS:

Muscle relaxation exercises, ABCD model (Healthypsych, 2014), Identifying cognitive faults and negative automatic thoughts, Strategies to cope with negative thoughts, Strategies to cope with stress, and Method of thought experimenting (Kleeberg, 2015).

These CBT interventions should be used for supporting MS patients in the future.

Working with those with MS on adequate coping strategies to improve their QoL might be helpful. Accepting MS and redefining boundaries in daily life as coping strategies turned out to be very important for those with MS, in our survey as well as in previous work (Hellige, 2002; Reynolds \& Prior, 2003).

Additionally, future interventions should focus on bringing to awareness the positive aspects of MS, as our survey identified that those with MS found benefits in their lives while living with MS. Mindfulness empowers the ability to slow down and observe. It supports improving affect regulation (Muñoz San José et al., 2016). Interventions focusing on compassion and mindfulness could be very constructive. 
Stress was mentioned frequently as a cause for worsening symptoms of MS or even causing MS (see Supplementary Materials for details). Psychoeducational courses on symptom- and stress-management (Dennison \& Moss-Morris, 2010; Madan \& Pakenham, 2014; Matud, 2004; Mund \& Mitte, 2012) and ways to self-manage life with MS would be beneficial. Selfmanagement instruments (Audulv, 2013; Corbin et al., 2004; Matud, 2004; Sauter et al., 2008; Wagner et al., 2012) should be offered to support chronically ill. They could be developed in the context of managing medication, coping with particularly bad episodes of MS, exercise, household activities, leisure time, work, lifestyle (such as nutrition), stress, emotions, identity, and fatigue. Recent investigations indicate that psychotherapeutic interventions for stress management, such as mindfulness-based interventions, could improve quality of life, depression, anxiety, and fatigue in MS patients. (Muñoz San José et al., 2016).

Oriented on our study results, working on personal characteristics, ways to improve self-esteem, increasing sociability, and developing ways to express love towards others would be constructive towards living and organizing a life with MS. Personalized interventions tailored to the patient's sex/gender would support especially men in finding ways to express love and be more social (see Supplementary Materials for details). Perceived self-efficacy is important for symptom self-management in chronic disease (Hoffman, 2013) and should be enhanced. Kim \& Youn (2015) showed significant improvements in chronic ill elderly Koreans when participating in the chronic disease self-management program.

Furthermore, negative experience with medical personnel was reported (see Supplementary Materials for details). Focusing on communication with medical personnel for future interventions seems to be fundamental for both sides, for those with MS and for their medical personnel.

\section{Social Support}

In our study, receiving social support is closely connected to high self-esteem, an ability to express love and being mindful. Charmaz (1983) found that in the course of the illness, the chronically ill become more restricted, which makes it harder to maintain social relationships. Losing the ability to do something makes it hard to sustain a meaningful life that bolsters selfworth. Therefore, it seems beneficial for future interventions to focus on ways to improve social support and maintain social relationships.

Those with MS pointed out partners and spouses as the most frequent sources of social support, followed by friends and parents (see Supplementary Materials for details). As these social support sources have to deal with challenges in their lives through MS in the familyalso (Qualls \& Williams, 2013) support groups targeted at MS caregivers would be beneficial (National multiple sclerosis society, 2015)

\section{Limitations}

Since our study was conducted in two languages, the survey questions and responses had to be translated, which could result in biases in the results. To counteract this as much as possible, the surveys were carefully translated and back-translated by independent parties to check for consistent interpretations. Another potential source of bias is the recruitment modality (inpatients vs. outpatients), which differed between the two legs of the survey for practical reasons. 
This might have potential consequences on study findings for comparing two different samples. As a consequence, the two samples differ in age, their disease progression, their MS duration and their educational level.

Although we controlled for these variables by using them as covariates in all quantitative analyses, we were unable to control for these variables in the qualitative analysis, and we thus analyzed separately (without making direct comparisons between the samples). For future research projects, we recommend using our identified coping strategies and let them be evaluated quantitatively by persons with MS. We recommend a bigger sample size including as many women as men.

We used portions of three questionnaires, which threatens the psychometric qualities of those instruments. Thus, the partial instruments may not be reliable and valid measures of the study's variables. (see Supplementary Materials, which questions of the BFIMSS had to be excluded for further calculations).

\title{
Conclusion
}

We identified national differences in social-emotional QoL as well as self-esteem of those with MS, and general differences in found benefits since having MS. We found that social-emotional QoL is equivalent for both women and men with MS. This can inform the development of psychological and social interventions for improving the social-emotional QoL of those with MS, independent of sex/gender. At the same time, we found that it is easier for women than men to express love towards others. Women and men also showed differences in their coping strategies for dealing with MS in Austria as well as in the US. Future interventions can be oriented toward sex/gender and national differences for improving social and emotional QoL in those with MS. Learning from each other may expand individuals' perception of living with MS.

\section{Acknowledgements}

We would like to thank Dr. Alexander Lex for feedback and comments on this manuscript, as well as Dr. Peter Griesshofer, Dr. Revere Kinkel, and Dr. Marion Stein, for local support at the clinics.

This work was funded by the Austrian Agency for International Cooperation in Education and Research (OEAD) through its Marietta Blau scholarship.

No author has any financial conflicts of interest.

\section{Explanations of abbreviations used:}

\author{
ANCOVA - Analysis of Covariance \\ AT - Austria \\ BFIMSS - Benefit finding \\ BFiMSS - Benefit Finding in Multiple Sclerosis Scale \\ BIDMC - Beth Israel Deaconess Medical Center Harvard Teaching Hospital, Boston \\ EDSS - Expanded Disability Status Scale
}


HALEMS/HAQUAMS - Hamburger Quality of Life in MS Questionnaire

HL- Heidemarie Lex

IRB - Institutional Review Board

MS - Multiple Sclerosis

Qol - quality of life

Social-emotional qol- social-emotional quality of life

Tpf - Trierer Persoenlichkeitsfragebogen

US - United States

\section{Bibliography}

Abbasi, S., Alimohammadi, N., \& Pahlavanzadeh, S. (2016). Effectiveness of Cognitive Behavioral Therapy on the Quality of Sleep in Women with Multiple Sclerosis: A Randomized Controlled Trial Study. International Journal of Community Based Nursing and Midwifery, 4(4), 320-328.

Ahadi, H., Laborda, J. G., Ozdamli, F., Maasoglu, Y., Ahadi, H., Delavar, A., \& Rostami, A. M. (2014). 5th World Conference on Educational SciencesComparing Coping Styles in MS Patients and Healthy Subjects. Procedia - Social and Behavioral Sciences, 116, 34543457. https://doi.org/10.1016/j.sbspro.2014.01.782

Alcalde-Cabero, E., Almazán-Isla, J., García-Merino, A., de Sá, J., \& de Pedro-Cuesta, J. (2013). Incidence of multiple sclerosis among European Economic Area populations, 1985-2009: the framework for monitoring. BMC Neurology, 13(1), 58. https://doi.org/10.1186/14712377-13-58

Audulv, A. (2013). The over time development of chronic illness self-management patterns: a longitudinal qualitative study. BMC Public Health, 13, 452. https://doi.org/10.1186/14712458-13-452

Backman, K., \& Hentinen, M. (2001). Factors associated with the self-care of home-dwelling elderly. Scandinavian Journal of Caring Sciences, 15(3), 195-202. https://doi.org/10.1046/j.1471-6712.2001.00007.x 
Baumhackl, U. (2011). Praevalenz der multiplen Sklerose 2010. Neurologisch-Fachmagazin Fuer Neurologie, 2011(2), 74.

Becker, P. (1989a). Der Trierer Persönlichkeitsfragebogen TPF. Handanweisung. Göttingen, Toronto, Zürich: Hogrefe. Retrieved from https://www.unifr.ch/ztd/HTS/inftest/WEBInformationssystem/de/4dee01/c94f826e2ced11d58b620001028b2ad7/hb.htm

Becker, P. (1989b). TPF Trierer Persoenlichkeitsfragebogen. Hogrefe Testzentrale. Retrieved from http://www.testzentrale.de/programm/trierer-personlichkeitsfragebogen.html

Boeije, H. R., Duijnstee, M. S. H., Grypdonck, M. H. F., \& Pool, A. (2002). Encountering the downward phase: biographical work in people with multiple sclerosis living at home. Social Science \& Medicine (1982), 55(6), 881-893.

Campbell, J. D., Ghushchyan, V., Brett McQueen, R., Cahoon-Metzger, S., Livingston, T., Vollmer, T., ... Nair, K. (2014). Burden of multiple sclerosis on direct, indirect costs and quality of life: National US estimates. Multiple Sclerosis and Related Disorders, 3(2), 227-236. https://doi.org/10.1016/j.msard.2013.09.004

Charmaz, K. (1983). Loss of self: a fundamental form of suffering in the chronically ill. Sociology of Health \& Illness, 5(2), 168-195.

Corbin, J. M., Strauss, A. L., \& Hildenbrand, A. (2004). Weiterleben lernen: Verlauf und Bewältigung chronischer Krankheit. Hans Huber.

Dennison, L., \& Moss-Morris, R. (2010). Cognitive-behavioral therapy: what benefits can it offer people with multiple sclerosis? Expert Review of Neurotherapeutics, 10(9), 13831390. https://doi.org/10.1586/ern.10.111

Elo, S., \& Kyngäs, H. (2008). The qualitative content analysis process. Journal of Advanced Nursing, 62(1), 107-115. https://doi.org/10.1111/j.1365-2648.2007.04569.x 
Fortin, M., Chouinard, M.-C., Bouhali, T., Dubois, M.-F., Gagnon, C., \& Bélanger, M. (2013). Evaluating the integration of chronic disease prevention and management services into primary health care. BMC Health Services Research, 13(1), 132. https://doi.org/10.1186/1472-6963-13-132

Garcia-Montojo, M., Dominguez-Mozo, M., Arias-Leal, A., Garcia-Martinez, A., De las Heras, V., Casanova, I., ... Perron, H. (2013). The DNA Copy Number of Human Endogenous Retrovirus-W (MSRV-Type) Is Increased in Multiple Sclerosis Patients and Is Influenced by Gender and Disease Severity. PLoS ONE, 8(1). https://doi.org/10.1371/journal.pone.0053623

Gold, S., Heesen, C., Schulz, H., Guder, U., Mönch, A., Gbadamosi, J., ... Schulz, K. (2001). Disease specific quality of life instruments in multiple sclerosis: validation of the Hamburg Quality of Life Questionnaire in Multiple Sclerosis (HAQUAMS). Multiple Sclerosis, 7(2), 119-130.

Grech, L. B., Kiropoulos, L. A., Kirby, K. M., Butler, E., Paine, M., \& Hester, R. (2016). Coping mediates and moderates the relationship between executive functions and psychological adjustment in multiple sclerosis. Neuropsychology, 30(3), 361-376. https://doi.org/10.1037/neu0000256

Harsh, Carry, \& Fox, R. (2000 - 2015). Disease Management. Retrieved from http://www.clevelandclinicmeded.com/medicalpubs/diseasemanagement/neurology/multi ple_sclerosis/

Healthypsych. (2014). Psychology Tools: A-B-C-D Model for Anger Management. Retrieved August 3, 2017, from https://healthypsych.com/psychology-tools-a-b-c-d-model-foranger-management/ 
Hellige, B. (2002). Balanceakt Multiple Sklerose: Leben und Pflege bei chronischer Krankheit. Kohlhammer.

Hoffman, A. J. (2013). Enhancing Self-Efficacy for Optimized Patient Outcomes through the Theory of Symptom Self-Management. Cancer Nursing, 36(1), E16-E26. https://doi.org/10.1097/NCC.0b013e31824a730a

Irvine, H., Davidson, C., Hoy, K., \& Lowe-Strong, A. (2009). Psychosocial adjustment to multiple sclerosis: exploration of identity redefinition. Disability and Rehabilitation, 31(8), 599-606. https://doi.org/10.1080/09638280802243286

Kim, S. H., \& Youn, C. H. (2015). Efficacy of Chronic Disease Self-management Program in Older Korean Adults with Low and High Health Literacy. Asian Nursing Research, 9(1), 42-46. https://doi.org/10.1016/j.anr.2014.10.008

Kleeberg, B. (2015). [Thought experiments, counterfactuality and self-understanding of the sciences around 1900]. Berichte Zur Wissenschaftsgeschichte, 38(1), 7-14. https://doi.org/10.1002/bewi.201501701

Kralik, D., Koch, T., \& Eastwood, S. (2003). The salience of the body: transition in sexual selfidentity for women living with multiple sclerosis. Journal of Advanced Nursing, 42(1), $11-20$.

Madan, S., \& Pakenham, K. I. (2014). The stress-buffering effects of hope on adjustment to multiple sclerosis. International Journal of Behavioral Medicine, 21(6), 877-890. https://doi.org/10.1007/s12529-013-9384-0

Matud, M. P. (2004). Gender differences in stress and coping styles. Personality and Individual Differences, 37(7), 1401-1415. https://doi.org/10.1016/j.paid.2004.01.010 
Moss-Morris, R., Dennison, L., Landau, S., Yardley, L., Silber, E., \& Chalder, T. (2013). A randomized controlled trial of cognitive behavioral therapy (CBT) for adjusting to multiple sclerosis (the saMS trial): does CBT work and for whom does it work? Journal of Consulting and Clinical Psychology, 81(2), 251-262. https://doi.org/10.1037/a0029132

Moss-Morris, R., Dennison, L., Yardley, L., Landau, S., Roche, S., McCrone, P., \& Chalder, T. (2009). Protocol for the saMS trial (supportive adjustment for multiple sclerosis): a randomized controlled trial comparing cognitive behavioral therapy to supportive listening for adjustment to multiple sclerosis. BMC Neurology, 9, 45. https://doi.org/10.1186/1471-2377-9-45

Mund, M., \& Mitte, K. (2012). The costs of repression: A meta-analysis on the relation between repressive coping and somatic diseases. Health Psychology, 31(5), 640-649. https://doi.org/10.1037/a0026257

Muñoz San José, A., Oreja-Guevara, C., Cebolla Lorenzo, S., Carrillo Notario, L., Rodríguez Vega, B., \& Bayón Pérez, C. (2016). Psychotherapeutic and psychosocial interventions for managing stress in multiple sclerosis: The contribution of mindfulness-based interventions. Neurología (English Edition), 31(2), 113-120. https://doi.org/10.1016/j.nrleng.2015.07.003

National multiple sclerosis society. (2015). A guide for caregivers. Retrieved March 9, 2017, from https://www.nationalmssociety.org/NationalMSSociety/media/MSNationalFiles/Brochure s/Brochure-A-Guide-for-Caregivers.pdf 
Pagnini, F., Bosma, C. M., Phillips, D., \& Langer, E. (2014). Symptom changes in multiple sclerosis following psychological interventions: a systematic review. BMC Neurology, 14, 222. https://doi.org/10.1186/s12883-014-0222-z

Pakenham, K. I., \& Cox, S. (2009). The dimensional structure of benefit finding in multiple sclerosis and relations with positive and negative adjustment: A longitudinal study. Psychology \& Health, 24(4), 373-393. https://doi.org/10.1080/08870440701832592

Qualls, S. H., \& Williams, A. A. (2013). Caregiver family therapy: Empowering families to meet the challenges of aging (Vol. x). Washington, DC, US: American Psychological Association.

Reynolds, F., \& Prior, S. (2003). "Sticking jewels in your life”: exploring women's strategies for negotiating an acceptable quality of life with multiple sclerosis. Qualitative Health Research, 13(9), 1225-1251.

Rintell, D. J., Frankel, D., Minden, S. L., \& Glanz, B. I. (2012). Patients’ perspectives on quality of mental health care for people with MS. General Hospital Psychiatry, 34(6), 604-610. https://doi.org/10.1016/j.genhosppsych.2012.04.001

Sauter, C., Zebenholzer, K., Hisakawa, J., Zeitlhofer, J., \& Vass, K. (2008). A longitudinal study on effects of a six-week course for energy conservation for multiple sclerosis patients. Multiple Sclerosis (Houndmills, Basingstoke, England), 14(4), 500-505. https://doi.org/10.1177/1352458507084649

Strober, L. B. (2016). Personality in multiple sclerosis (MS): impact on health, psychological well-being, coping, and overall quality of life. Psychology, Health \& Medicine, 1-10. https://doi.org/10.1080/13548506.2016.1164321 
Stüve, O., \& Oksenberg, J. (2006). Multiple Sclerosis Overview. In R. A. R. A. Pagon, T. D. T. D. Bird, C. R. C. R. Dolan, K. K. Stephens, \& M. P. M. P. Adam (Eds.), GeneReviews ${ }^{T M}$. Seattle (WA): University of Washington, Seattle. Retrieved from http://www.ncbi.nlm.nih.gov/pubmed/20301492

Thomas, P. W., Thomas, S., Hillier, C., Galvin, K., \& Baker, R. (2006). Psychological interventions for multiple sclerosis. The Cochrane Database of Systematic Reviews, (1), CD004431. https://doi.org/10.1002/14651858.CD004431.pub2

Tillack, K., Naegele, M., Haueis, C., Schippling, S., Wandinger, K.-P., Martin, R., \& Sospedra, M. (2013). Gender differences in circulating levels of neutrophil extracellular traps in serum of multiple sclerosis patients. Journal of Neuroimmunology.

Wagner, G., Penelo, E., Wanner, C., Gwinner, P., Trofaier, M.-L., Imgart, H., ... Karwautz, A. F. K. (2012). Internet-delivered cognitive-behavioural therapy v. conventional guided self-help for bulimia nervosa: long-term evaluation of a randomised controlled trial. The British Journal of Psychiatry, 202(2), 135-141. https://doi.org/10.1192/bjp.bp.111.098582 